\title{
Why Are Our Rankings So White?
}

\author{
University Wankings
}

\begin{abstract}
University rankings are a highly visible means, globally and often nationally, of identifying where the purportedly best universities are to study, work, or to commission research in. However, they are deeply problematic, in terms of their methodological and philosophical underpinnings, as well as in their outcomes. These 'league tables' claim to be objective measures of quality - however, their internal logics and the measures they use create, maintain and project the global superiority of a particular form of higher education, ergo that of the Global North. It is no accident that they are dominated by 'Western' universities. This chapter argues that their approach is characteristic of cultural Whiteness, the centring of a particular Eurocentric cultural orientation which ignores or denigrates alternative perspectives. Furthermore, the academically and therefore socially - selective nature of those 'top' universities ensures that those institutions are predominantly studied at, and worked in, by demographically white social groups. This, we argue, is a morally indefensible position, in that it serves to reproduce social and philosophical inequalities. What is needed in higher education is the promotion of a more inclusive and egalitarian ethos in higher education, and in this there is no place for university rankings.
\end{abstract}

\section{Keywords}

rankings - university rankings - whiteness - higher education

University Wankings (UW) have been educated in, and live and work in, institutions and cities in the UK which have strong associations with - and therefore continue to benefit from - the British imperial project and the global slave trade (Bhambra et al., 2018). That we also work in high status institutions provides us with undeserving but significant privilege, both nationally and internationally. The form, language and references of this piece are largely 
Eurocentric, and we are writing in our mother tongue, the globally imposed academic lingua franca (Kedzierski, 2016), and this provides us with further 'accidental' advantages. As we discuss in due course, these elements of international status, of Eurocentrism, and language (among other things) overhelmingly favour particular kinds of scholars and scholarship in certain locations. In other words, we benefit from being situated at the centre, rather than the periphery. The default position after acknowledging this might be to say 'these things aside, our argument is as follows'. However, these issues are not 'aside', but hide in plain sight - they shape everything we say, how we say it, and how we are received. That we are not presenting our work in other equally valuable ways is, in part, a mark of our own failure to explore, develop, and embrace alternative approaches. This chapter represents a work in progress, in terms of our increasing understanding and discussion of systemic discrimination and our own complicity within it. It should also be mentioned that this chapter was largely written during strike action protesting against issues in higher education around excessive workloads, the prevalence of precarious working conditions, pay gaps between social groups, and attempts to undermine the pensions of many university staff. These issues are entangled with rankings and the logic that underpins them.

\section{$2 \quad$ Where Is the Quality in Higher Education?}

The world seems to be obsessed with rankings in every walk of life. Countries are ranked for their performance in every possible domain, from the Olympics to their quality of life. (Salmi \& Saroyan, 2007, p. 91)

An examination of any global university ranking immediately lays bear stark geographical imbalances in terms of which countries and regions appear most often, and which do not (Kaba, 2012; Jöns \& Hoyler, 2013). Taking the Times Higher Education (THE) World University Rankings (THE, 202O) as an example, of the purportedly 'top 30o' universities in the world, 270 (90\%) are located in Europe, North America, Australia and New Zealand. Of the remainder, 25 are from a small number of East Asian countries and there are only 5 from the rest of the world. Taking a slightly different angle, $282(94 \%)$ are located in the so-called 'Global North' of high income countries as specified by the World Bank (2019). The entire continent of Africa is represented by three institutions, all of which are in South Africa. There is only one university from the whole of Latin America, one from the Middle East, and not a single institution from Central Asia. THE is not alone in this bias - the Academic Ranking of World 
Universities (ARWU, 2019) and QS World University Rankings (QS, 2019) are more geographically inclusive, but only by a few percentage points.

What does this tell us? The message seems clear - 'world class' status, 'quality', or 'excellence' are highly concentrated in specific places. It is therefore, by implication, not present in others. Scholars of educational, health, or other inequalities, though, have long noted that underlying structures invariably create, maintain and often exacerbate social inequalities. In other words, it is not about the cream rising to the top, but rather about the presence of a system in which the cream identifies itself as better and utilises systemic processes to stay there. The QS rankings site - accompanied by a picture of a lion, the metaphorical king of the jungle - asks "Who Rules" (QS, 2019) in the world of universities? As we will see, rankings are a question of sovereignty, of control, where the balance of power - and therefore status and funding - rests in the hands of a small minority of majority white countries and institutions.

Rankings form part of a complex and growing array, worldwide, of assessment and accountability regimes created by governments, third party agencies like the OECD and World Bank, and commercial organisations such as QS and THE (Dale, 2005; Lo, 2011). These regimes are associated with a 'neoliberal' turn in the public sector whereby, in the case of higher education, national governments cede control over - and therefore responsibility for - educational outcomes by creating market conditions within which universities compete for students and funding (Olssen \& Peters, 2005). The professed rationale here is that competition encourages the 'players' to increase their standards and efficiency in teaching and research, and in doing so promote the interests of national positioning in the global 'knowledge economy'. Rankings purport to show where the best quality lies, and therefore where the best places to study, work, or commission research are. However, there is a fundamental fault line running through this assertion, in that rankings articulate a singular, universal model of 'good' which provides a particular kind of university - and thus a specific social group - with leading status and an unassailable advantage.

Rankings' competitive framing around orderly and 'objective' numerical criteria creates a 'façade of scientific neutrality' (Ordorika \& Lloyd, 2015). However, behind this façade sits a hegemonic project and worldview that is anything but neutral - Whiteness. By way of explanation, Keating (1995) helpfully draws a distinction between white in what we might consider racial/-ised terms and Whiteness in a cultural sense. They overlap through whites being 
the dominant economic group, being held in a central position by a Whiteness which they are unaware of, and which is only discernible in contrast to alternative worldviews which it classifies as 'other', as inferior. Ahmed (2007) further explains that Whiteness operates as a 'straightening device', whereby those who do not internalise and conform to its dominant norms are punished through exclusion. We can see this with rankings in that those which do not measure up - literally - to the imposed model of higher education 'excellence' are not considered part of the 'world class' club. This operates as a homogenising force (Ordorika \& Lloyd, 2015) since the only way to join the club, to be seen as excellent, is to play the game and try to catch up, although the system is designed in a way that makes this extremely difficult, if not impossible. Overall, this reinforces the assertion that only a small number of universities in the world are creditable. The THE World University Rankings $202 \mathrm{O}$ boast of being "the largest and most diverse university rankings" by including "almost 1,400 universities across 92 countries" (THE, 202O). This is $5 \%$ of the approximately 27 , ooo universities worldwide, in over 190 countries.

There is a considerable body of literature on rankings, much of which is heavily critical of both their ends as well as their means (Shahjahan et al., 2017). In terms of the former, the recognition of their reliance on (i.e. favouritism for) an Anglo-American model of higher education is prominent (Lo, 2011; Jöns \& Hoyler, 2013), and some have noted the close correlation between the former colonial powers' wealth and networks, and rankings (Kaba, 2012). In order to see how this plays out, it is necessary to examine how rankings are constructed. There is no shortage of critique on what Salmi and Saroyan (2007) describe as their significant methodological shortcomings. It is curious, though, that in spite of a sustained attack on this front, their considerable influence at both policy and local (i.e. organisational) level shows little sign of waning (Jöns \& Hoyler, 2013). It is paradoxical that universities, which are oriented above all else on the production, assessment, and dissemination of high quality knowledge, so avidly orient themselves around these poor quality, partial, and ideologically biased models.

Shahjahan et al. (2017) see that some of the critique of rankings' measurements assumes that if these were fairer and more accurate, then the rankings in themselves would be justified. However, we agree with their position, which is that the notion of a one-size-fits-all, competitive framework is inappropriate, in that it is not in the best interests of a collegial and diverse higher education. It matters not how 'inclusive' the rankings are, how multifaceted and complex they may be, or the extent to which they allow for culturally different models of higher education to be included and celebrated. Rankings are wrong because they are, by their very nature, othering. Our examination of how they 
are constructed here is a way of examining how the odds are initially - and remain - permanently stacked towards certain kinds of universities in particular geographical regions, and therefore against others.

Common to many rankings is the inclusion of academic publications and citations (e.g. ARWU, 2019; THE, 202O). At face value, this appears to be a commonsense approach, in that the universities who publish the most work, and work which is most highly cited - i.e. considered important - by others is a sign of strong quality. However, this assumes that scholars, globally, have access to, and a good understanding of, all work in their field. This an assumption which falls apart rapidly on closer examination, not least because of the prohibitive paywalls which surround scholarly literature. Also, while the precise figure varies by discipline, citations in fact follow an 80:20 ratio, where $80 \%$ of scholarly work cites a mere $20 \%$ of existing publications (Sugimoto \& Larivière, 2018). Within this, there is a huge English language and therefore Global North bias, which places particular, well-established journals at the centre. Furthermore, the nature of academic publication and its gatekeeping practices ensures the dominance of White perspectives and knowledge construction, and thus marginalises alternate voices, perspectives, and methodologies (Baffoe et al., 2014; Hopkins et al., 2013). In combination, these elements ensure the preservation of an ongoing colonial legacy in both academic knowledge production and dissemination (Confraria et al., 2017).

The THE University Ranking includes a category called 'international outlook', which considers the proportion of international staff, students, and collaborations (THE, 2020). The rationale looks sensible, in that the best universities would attract more international interest, but again this assumes near-perfect knowledge of the system, worldwide, as well as easy cross-border mobility and an absence of any language barriers. Academic mobility has exploded in recent years, but the lines of movement for researchers invariably lead away from the Global South (Bilecen \& Van Mol, 2017; Kim, 2009). The same is true for students, not least because many Global North universities aggressively recruit wealthy, fee-paying international students as a financial survival strategy (Graf, 2009; Waters, 2012). Waters (2012) notes again how language features in these transnational flows in that "English-medium education, with all the colonial baggage that implies, retains to a large degree its 'value' in a global [higher education] market" (p. 127).

Similarly, measures such as 'reputation' - see THE's Academic Reputation Survey (THE, 202O), for example - are absurdly self-referential, whereby the organisation which curates and heavily markets a list of the 'best' universities asks a (limited) sample of academics which universities they think are world leaders (Hazelkorn, 2014; Rocha, 2018). Research income and staff-student 
ratios, too, inordinately favour older, larger, wealthier - and particularly STEMoriented universities; Hazelkorn (2008) estimates that being a world-leading university is a $\$ 1$ bn undertaking. Overall, we can see that rankings are a selffulfilling prophecy, whereby the winners attract more (international) students and staff, more funding, more publications, more status, and thereby further consolidate their reputations at the expense of others. Rankings change very little over time, not least because universities are not agile in the way that markets and rankings assume. The precise functioning of commercial rankings is a black box (Wilsdon, 2015), and there is no way of knowing whether the changes in placings are due to genuine organisational change or simply tweaks in the algorithms to give the perception that universities can improve their positioning from one year to the next.

\section{4 Top (White) Universities}

Top universities are also demographically white. In addition to being located bar a small minority - in countries with majority white (often Anglo-) European populations, the education systems in those countries are demonstrably and systematically racist. High status universities, sitting as they do at the apex of these systems, are invariably also socially exclusive.

Social scientists have for decades recognised a strong inegalitarian relationship between educational outcomes and background factors, where social disadvantage intersects with other dimensions such as race. In spite of being comparatively wealthy, many of the countries which feature most strongly in the global university rankings also exhibit marked educational and other inequalities. Social disadvantage, alongside race, is known to be a key predictor of lower educational outcomes and/or progression to university, and we see evidence of this from New Zealand (Juhong \& Maloney, 2006) to the Netherlands (Stevens et al., 2011), from France and Germany (Duru-Bellat et al,. 2008) to the USA (McDaniel et al., 2011).

We can also see that the educational attainment of indigenous populations is of major concern in Canada (Gordon \& White, 2014), New Zealand (Nash, 2001), Australia (Bradley et al., 2007), and the USA (Jacob, 2017). Overall, those who do less well at school are less likely to (be encouraged to) apply to university, and particularly to the highest status universities whose fiercely competitive entrance requirements and costs are likely to exclude them anyway. This results in a lack of minority ethnic representation in those institutions, as well as in the academic profession in general (Beutel \& Nelson, 2006; Bhopal, 2016; Henry et al., 2017). 
To examine how this works in practice, educational trajectories in the UK offer a useful example. Countries present their own unique combination of cultural, political, and economic conditions in and around education (Robertson \& Dale, 2015), and we would not expect the conditions there to be exactly mirrored elsewhere. However, as we have noted above, the relationship between social and educational inequalities is a common phenomenon, so many of the same factors will be at play, albeit with different weights and combinations.

It has been well-documented that Black pupils perform less well at school in the UK, and this relative under-achievement has proven resilient over time (Mirza, 2005). Gillborn (2005) goes as far to say that, in education in England, "the routine assumptions that structure the system encode a deep privileging of white students and, in particular, the legitimisation, defence and extension of Black inequity" (p. 496). Institutional racism means that Black pupils are more likely to be placed in lower attaining classes and/or not be admitted to the high performing schools which send more of their pupils to elite universities. Furthermore, Black pupils are far more likely to be excluded from schools for behavioural reasons than other social groups (Parsons, 2008).

One perhaps surprising trend is that, despite these barriers to strong educational achievement, Black pupils progress to higher education at relatively high rates. They do, though, report feeling underprepared for university studies and a high proportion experience both institutional and personal racism (NUS, 2011). The corollary of this is that they are more likely to achieve lower degree scores - or drop out of university entirely - than other students (Richardson, 2009). Black students are also underrepresented at high status universities. This is in part due to their propensity not to apply (for attainment/cultural reasons). Even for those that do apply, they are far less likely to be offered a place than their counterparts from other majority and minority ethnic groups (Boliver, 2016). While ethnic minority students make up $24 \%$ of the UK-domiciled student body and Black students $7 \%$ (Advance $\mathrm{HE}, 2 \mathrm{O}$ gb), last year the latter only made up $2.6 \%$ of domestic students at THE's global \#1 university, the University of Oxford. It should be noted that this marks a significant improvement - in 2014 they comprised a mere 1.1\% (Oxford University, 2019).

This lack of a Black presence in student bodies at the 'top' universities has significant knock-on effects, through doctoral study and into academia, not least because, firstly, students tend to stay in their university type (elite/nonelite) as they progress past undergraduate level (Pásztor and Wakeling, 2018). In other words, if they do not enter a high-status university from the outset, they are unlikely to undertake doctoral studies there - assuming they are able to score well enough and stay on the course. Secondly, research and doctoral funding/capacity is overwhelmingly located in those higher status universities 
- nationally they award almost 90\% of all doctorates (Budd et al., 2018). Black students made up $3 \%$ of the entire national doctoral student body in 2017-18, and only $1.2 \%$ of those were in receipt of state funding (Williams et al., 2019). Progressing into academia, only $10 \%$ of academics are from ethnic minority groups and only $3 \%$ are Black (Advance HE, 2019a). Numbers are rising, but Black academics are more likely to be in junior positions and not on permanent contacts. Black staff are particularly underrepresented at senior levels, occupying very few leadership positions, and a study by Bhopal (2016) reports that they regularly face career progression issues. Most tellingly, the UK professoriate is $85 \%$ white and o.6\% Black (Advance HE, 2019a). We can see then, that and why universities, and particularly top universities, are overwhelmingly demographically White spaces.

\section{5 \\ Conclusions}

Global university rankings can then, be seen as an act of white supremacy (see Gillborn, 2005) in that they systematically establish and preserve the dominance of a tiny selection of elitist universities in the white majority Global North. Those 'top' universities, too, are predominantly white in terms of their staff and students, due to their particular positions within those of those countries' institutionally racist education systems. Furthermore, rankings implicitly support epistemicide (Santos, 2016) through their continued promotion of exclusive and culturally White forms and structures of knowledge production and dissemination.

How might rankers respond to this assertion? They may claim that the presence of some 'universities of colour' in East Asia, Africa, the Middle East, and Latin America, are evidence that they are not racist. They simply crunched the numbers - it is not their fault that 'the winners' are who and where they are. However, not only did they create a model which explicitly others the vast majority of global universities and alternative epistemologies, and particularly those in and of the Global South, the very act of ranking is, in itself, an exercise in Whiteness.

The question which remains is how we might encourage universities to be more socially progressive in terms of their admissions and employment practices, collaboration, cultural inclusivity, social and environmental responsibility, and so on? Organisational theorists suggest that change comes about through four overlapping but distinct mechanisms: competition, coercion, mimesis and normativity (DiMaggio \& Powell, 1983). Competition, in the form of rankings, selective funding and so on, as we have seen, permanently favours 
a select few. There are 'progressive' rankings across elements, such as staff and student diversity (UW, 2019), environmental sustainability (People \& Planet, 2019) and THE even has its own global 'Impact' ranking, based on some of the United Nations' Sustainable Development Goals (THE, 2019). Rankings clearly have leverage, but their methodological and philosophical flaws mean that good performance may only be skin deep, and they still produce/reinforce hierarchies. Coercion relates primarily to government policy, and in the UK, for example, universities are tasked with improving the diversity of their admissions, as well as the outcomes for disadvantaged and/or minority students (OfS, 2020). At the same time, though, funding and status are allocated on the basis of research quality and selectivity, which operates in tension with equity and inclusion. Mimesis occurs through the imitation of leaders in the field, but the leaders are the ones we clearly do not want to follow in terms of progressiveness! Normativity, on the other hand, relates to the values and practices that underpin professions - essentially the culture of a sector.

Higher education is paradoxical in the sense that, normatively, it promotes the extension of knowledge but does not apply its own findings in practice much of the most advanced thinking on management practices, the environment and social equity emerges from universities, but the ongoing pervasive structural influence of Whiteness, among other things, limits its capacity to act differently. What is needed is a sea change in how universities are valued, funded, and governed, according to a fundamentally different understanding of their purposes and logics. However, the current winners - White, Europeanstyle universities - will resist such moves as it would mean relinquishing their position at the apex of the higher education food chain.

\section{References}

Advance HE. (2019a). Equality + higher education: Staff statistical report 2019. Author. https://www.advance-he.ac.uk/knowledge-hub/equality-higher-educationstatistical-report-2019

Advance HE. (2019b). Equality + higher education: Student statistical report 2019. Author. https://www.advance-he.ac.uk/knowledge-hub/equality-higher-educationstatistical-report-2019

Ahmed, S. (2007). A phenomenology of whiteness. Feminist Theory, 8(2), 149-168.

ARWU. (2019). Academic ranking of world universities. Author.

http://www.shanghairanking.com/

Baffoe, M., Asimeng-Boahene, L., \& Ogbuagu, B. C. (2014). Their way or no way: "Whiteness" as agent for marginalizing and silencing minority voices in academic research and publication. European Journal of Sustainable Development, 3(1), 13-32. 
Beutel, A. M., \& Nelson, D. J. (2006). The gender and race-ethnicity of faculty in top social science research departments. The Social Science Journal, 43(1), 111-125.

Bhambra, G. K., Gebrial, D., \& Nişancıolu, K. (2018). Decolonising the university. Pluto Press.

Bhopal, K. (2016). The experiences of Black and minority ethnic academics: A comparative study of the unequal academy. Routledge.

Bilecen, B., \& Van Mol, C. (2017). Introduction: International academic mobility and inequalities. Journal of Ethnic and Migration Studies, 43(8), 1241-1255.

Boliver, V. (2016). Exploring ethnic inequalities in admission to Russell Group Universities. Sociology, 5o(2), 247-266.

Bradley, S., Draca, M., Green, C., \& Leeves, G. (2007). The magnitude of educational disadvantage of indigenous minority groups in Australia. Journal of Population Economics, 2O(3), 547-569.

Budd, R., O'Connell, C., Yuan, T., \& Ververi, O. (2018). The DTC Effect: ESRC doctoral training centres and the UK social science doctoral training landscape. Liverpool Hope University Press.

Confraria, H., Mira Godinho, M., \& Wang, L. (2017). Determinants of citation impact: A comparative analysis of the Global South versus the Global North. Research Policy, 46(1), 265-279.

Dale, R. (2005). Globalisation, knowledge economy and comparative education. Comparative Education, 41(2), 117-149.

DiMaggio, P. J., \& Powell, W. W. (1983). The iron cage revisited: Institutional ismorphism and colective rationality in organizational fields. American Sociological Review, $48(2), 147-16$ o.

Duru-Bellat, M., Kieffer, A., \& Reimer, D. (2008). Patterns of social inequalities in access to higher education in France and Germany. International Journal of Comparative Sociology, 49(4-5), 347-368.

Gillborn, D. (2005). Education policy as an act of white supremacy: Whiteness, critical race theory and education reform. Journal of Education Policy, 20(4), 485-505.

Gordon, C. E., \& White, J. P. (2014). Indigenous educational attainment in Canada. International Indigenous Policy Journal, 5(3).

Graf, L. (2009). Applying the varieties of capitalism approach to higher education: Comparing the internationalisation of German and British universities. European Journal of Education, 44(4), 569-585.

Hazelkorn, E. (2008). Learning to live with league tables and ranking: The experience of institutional leaders. Higher Education Policy, 21, 193-215.

Hazelkorn, E. (2014). Reflections on a decade of global rankings: What we've learned and outstanding issues: Ellen Hazelkorn. European Journal of Education, 49(1), 12-28.

Henry, F., Dua, E., Kobayashi, A., James, C., Li, P., Ramos, H., \& Smith, M. S. (2017). Race, racialization and indigeneity in Canadian universities. Race Ethnicity and Education, 20(3), 300-314. 
Hopkins, A. L., Jawitz, J. W., McCarty, C., Goldman, A., \& Basu, N. B. (2013). Disparities in publication patterns by gender, race and ethnicity based on a survey of a random sample of authors. Scientometrics, 96(2), 515-534.

Jacob, M. (2017). Indigenous studies speaks to American sociology: The need for individual and social transformations of Indigenous education in the USA. Social Sciences, $7(2), 1$.

Jöns, H., \& Hoyler, M. (2013). Global geographies of higher education: The perspective of world university rankings. Geoforum, 46, 45-59.

Juhong, B., \& Maloney, T. (2006). Ethnicity and academic success at university. New Zealand Economic Papers, 40(2), 181-213.

Kaba, A. J. (2012). Analyzing the Anglo-American Hegemony in the times higher education rankings. Education Policy Analysis Archives, 20(21), 1-53.

Keating, A. (1995). Interrogating 'whiteness', (de)constructing 'race'. College English, $57(8), 901-908$.

Kedzierski, M. (2016). English as a medium of instruction in East Asia's higher education sector: A critical realist cultural political economy analysis of underlying logics. Comparative Education, 52(3), 375-391.

Kim, T. (2009). Transnational academic mobility, internationalization and interculturality in higher education. Intercultural Education, 20(5), 395-405.

Lo, W. W. Y. (2011). Soft power, university rankings and knowledge production: Distinctions between hegemony and self-determination in higher education. Comparative Education, 47(2), 209-222.

McDaniel, A., DiPrete, T. A., Buchmann, C., \& Shwed, U. (2011). The Black gender gap in educational attainment: Historical trends and racial comparisons. Demography, $48(3), 889-914$.

Mirza, H. S. (2005). 'The more things change, the more they stay the same': Assessing Black underachievement 35 years on. In B. Richardson (Ed.), Tell it like it is: How our schools fail Black children (pp. 111-119). Bookmarks - Trentham Books Ltd.

Nash, R. (2001). Models of Maori educational attainment: Beyond the 'class' and 'ethnicity' debate. Waikato Journal of Education, 7, 23-36.

NUS. (2011). Race for equality: A report on the experiences of Black students in further and higher education. In Race for equality (pp. 1-68). National Union of Students.

OfS. (2020). Promoting equal opportunities. Author. https://www.officeforstudents.org. uk/advice-and-guidance/promoting-equal-opportunities/

Olssen, M., \& Peters, M. A. (2005). Neoliberalism, higher education and the knowledge economy: From the free market to knowledge capitalism. Journal of Educational Policy, 20(3), 313-345.

Ordorika, I., \& Lloyd, M. (2015). International rankings and the contest for university hegemony.Journal of Education Policy, 30(3), 385-405. 
Oxford University. (2019). Undergraduate admissions statistics current: Ethnicity. Undergraduate Admissions Statistics Current. https://www.ox.ac.uk/about/facts-andfigures/admissions-statistics/undergraduate-students/current/ethnicity?wssl=1\#

Parsons, C. (2008). Race relations legislation, ethnicity and disproportionality in school exclusions in England. Cambridge Journal of Education, 38(3), 401-419.

Pásztor, A., \& Wakeling, P. (2018). All PhDs are equal but ... Institutional and social stratification in access to the doctorate. British Journal of Sociology of Education, 5692, 1-16.

People \& Planet. (2019). 2019 University league. Author. https://www.savethestudent.org/ extra-guides/university-sustainability-environment-league-table.html

QS. (2019). QS world university rankings. Top Universities.

https://www.topuniversities.com/university-rankings/world-university-rankings/ 2020

Richardson, J. T. E. (2009). The academic attainment of students with disabilities in UK higher education. Studies in Higher Education, 34(2), 123-137.

Robertson, S. L., \& Dale, R. (2015). Towards a 'critical cultural political economy' account of the globalising of education. Globalisation, Societies and Education, 13(1), 149-170.

Rocha, L. (2018). What's inside the times higher education world university rankings' 'academic reputation survey'? USS briefs. https://medium.com/ussbriefs/whatsinside-the-times-higher-education-world-university-rankings-academic-reputationsurvey-e16fo476f 720

Salmi, J., \& Saroyan, A. (2007). League tables as policy instruments: The political economy of accountability in tertiary education. In Global University Network for Innovation (GUNI), higher education in the world. Accreditation for quality assurance: What is at stake? (pp. 79-96). Macmillan.

Santos, B. de S. (2016). Epistemologies of the South: Justice against epistemicide. Routledge.

Shahjahan, R. A., Blanco Ramirez, G., \& Andreotti, V. de O. (2017). Attempting to Imagine the Unimaginable: A decolonial reading of global university rankings. Comparative Education Review, $67\left(\mathrm{~S}_{1}\right), \mathrm{S}_{51}-\mathrm{S}_{73}$.

Stevens, P. A. J., Clycq, N., Timmerman, C., \& Van Houtte, M. (2011). Researching race/ ethnicity and educational inequality in the Netherlands: A critical review of the research literature between 1980 and 2008. British Educational Research Journal, $37(1), 5^{-43}$.

Sugimoto, C. R., \& Larivière, V. (2018). Measuring research: What everyone needs to know. Oxford University Press.

THE. (2019). Impact rankings 2019. THE World University Rankings. https://www.timeshighereducation.com/rankings/impact/2019/overall\#!/page/o/ length/25/sort_by/rank/sort_order/asc/cols/undefined 
THE. (2020). World university rankings. Times Higher Education World University Rankings. https://www.timeshighereducation.com/world-university-rankings/ 2020/world-ranking\#!/page/o/length/25/sort_by/rank/sort_order/asc/cols/stats

UW. (2019). The UK PUR. UK Progressive University Rankings. https://ukpur.home.blog/ Waters, J. L. (2012). Geographies of international education: Mobilities and the reproduction of social (dis)advantage: Geographies of international education. Geography Compass, 6(3), 123-136.

Williams, P., Bath, S., Arday, J., \& Lewis, C. (2019). The Broken Pipeline (p. 8). Leading Routes.

Wilsdon, J. (2015). The Metric Tide: The independent review of the role of metrics in research assessment \& management. Sage Publications Ltd.

World Bank. (2019). High income countries. Author. https://data.worldbank.org/ income-level/high-income 